\title{
Does old age have an effect on Acute Mountain Sickness? A systematic review
}

Running title: Acute mountain sickness in the older traveller

\author{
Vincenza Gianfredi, MD ${ }^{1}$ \\ Luciana Albano, $\mathrm{MD}^{2}$ \\ Buddha Basnyat, MD, MSc, FACP, FRCP ${ }^{3}$ \\ Pietro Ferrara, $\mathrm{MD}^{2 *}$
}

\section{Affiliations}

1. Post-graduate School of Hygiene and Preventive Medicine, Department of Experimental Medicine, University of Perugia, Perugia, Italy

2. Department of Experimental Medicine, University of Campania "Luigi Vanvitelli", Naples, Italy

3. Oxford University Clinical Research Unit, Patan Academy of Health Sciences, Kathmandu, Nepal.

\section{Word Count}

Abstract: 232

Main Text: 3,135

\section{Corresponding author}

\section{Pietro Ferrara, MD}

University of Campania "Luigi Vanvitelli"

5, Via Luciano Armanni

80138 Naples, Italy

+390815667716

p_ferrara@alice.it 


\begin{abstract}
Acute mountain sickness (AMS) is the most common form of illness at high altitude; however, it is still unclear whether age is a protective factor or a risk factor for the development of AMS in travellers. In recent decades, the number of travellers aged 60 years or older is increasing. Thus, the care of older travellers is a longstanding issue in travel medicine. This study aims to systematically review the current state of knowledge related to the effect of old age on the extent of AMS. Preferred Reporting Items for Systematic Reviews and Meta-Analyses (PRISMA) guidelines were used, and the following databases were consulted: PubMed/Medline, Embase, Europe PubMed Central (EuropePMC), World Health Organization Library Database (WHOLIS), Literatura LatinoAmericana e do Caribe em Ciências da Saúde (LILACS). The search yielded a total of 532 articles, of which 25 met the inclusion criteria, corresponding to 26 reports. Although the approaches, methods, and quality were heterogeneous among the included studies, 12 reported a negative correlation between AMS prevalence and age, 11 detected no relationship, and three papers indicated that the age of AMS subjects was significantly higher than controls. Despite these differences, old age does not seem to be a contraindication for travelling at high altitude. Thus, the presented synthesis will be useful for health professionals in travel medicine to better tailor their appropriate care for older adults who travel to destinations at high altitude.
\end{abstract}

Key words: acute mountain sickness; ageing; altitude sickness; elderly; older travellers; travel medicine 


\section{Introduction}

High-altitude destinations have traditionally attracted travellers for trekking, pilgrimage, leisure, and business reasons. ${ }^{1,2}$ Going high, especially ascending to a great height too quickly, may cause several illness or injuries among travellers. Acute mountain sickness (AMS) is the most common form of illness at high altitude. Its symptoms are non-specific and include headaches accompanied by anorexia, nausea, vomiting, fatigue, weakness, dizziness. These symptoms appear 2-12 hours after the ascent and are usually self-limiting, although they may be incapacitating. ${ }^{3}$

In recent decades, the number of high-altitude travellers has increased dramatically and also includes an increasingly significant proportion of adults aged 60 years or older. ${ }^{4,5}$ Although age is not a disease per se, normal ageing results in changes in physical activity and functional fitness, ${ }^{6}$ and older travellers may become more susceptible to travel-related insults, such as infections or traumas. ${ }^{7,8}$ The relevant changes may affect the respiratory system, with diminished ventilatory response to hypoxia and hypercapnia, which means that older people are more vulnerable during high-demand conditions. ${ }^{9}$ Older people are more likely to have pre-existing medical conditions that might decelerate or inhibit their acclimatization at high altitudes. ${ }^{10}$ Nevertheless, it is unclear whether these changes impact the extent of AMS in older persons.

Previous primary studies of the relationship between age and AMS risk yielded conflicting findings. Some studies identified age as a protective factor ${ }^{11,12}$ or a risk factor, ${ }^{13,14}$ but many other studies did not show any significant association. ${ }^{15-17}$ For these reasons, this systematic review aims to summarise the current state of knowledge related to the effect of old age on the extent of AMS.

\section{Methods}

\section{Protocol and registration}

The protocol for this review was registered in the Prospective Register of Systematic Reviews (PROSPERO) (number CRD42019128976). ${ }^{18}$ This systematic review was conducted according to Preferred Reporting Items for Systematic Reviews and Meta-Analyses (PRISMA) guidelines. ${ }^{19}$ 


\section{Participants and comparators}

Participants were older adults (defined as subjects aged 60 years or over), who visited high-altitude destinations. The cut-off point of 60 years old followed the United Nations' definition for old age. ${ }^{20}$ The comparators were travellers younger than 60 years old.

\section{Search strategy}

Six main databases were consulted, including PubMed/Medline, Embase, Europe PubMed Central (EuropePMC), (World Health Organization Library Database (WHOLIS), Literatura LatinoAmericana e do Caribe em Ciências da Saúde (LILACS). These databases were trawled from inception to 31st March 2019 without time filter. However, only English articles were included in our review. The search strategy developed for this review included three main aspects: travellers, older persons, and AMS. MeSH and text words were combined with Boolean operators AND and OR. The full search strategy is: (((((()(((“"Aged”[Mesh]) OR “Aging”[Mesh]) OR “Middle Aged”[MeSH Terms])) OR adult[Title/Abstract]) OR adults[Title/Abstract]))) AND $\quad((((((“ A l t i t u d e$ Sickness"[Mesh]) OR “altitude illness"[Title/Abstract]) OR “altitude sickness”[Title/Abstract]) OR “mountain sickness”[Title/Abstract]) OR “mountain illness”[Title/Abstract]))) AND (((“Risk Factors"[Mesh]) OR “epidemiology” [Subheading]) OR ("prevention and control” [Subheading])))). The search strategy was adjusted slightly according to the evaluated databases. The lists of references of the included studies were manually screened in order to include relevant papers not retrieved previously. Contacts with authors were rehearsed to address doubts regarding missing or incomplete data in the reports studied for the inclusion.

\section{Inclusion/exclusion criteria and quality assessment}

Studies that fulfilled the inclusion criteria were considered in this review. Papers aiming to investigate the role of age as risk factor for AMS in older adults were considered eligible. In order to be included in the review, the reports should be published as primary studies, trial or observational studies (casecontrol, cohort or cross-sectional studies). Only original articles were included in this evaluation. Records that met the following criteria were excluded: (1) studies including population other than 
travellers; (2) not considering age as predictors for AMS; (3) published as review, editorial, or letter to editor.

\section{Study selection, data extraction and synthesis}

Two independent and blinded reviewers (VG and PF) screened the titles and abstracts, in order to identify the potentially relevant articles. Disagreements were solved through discussion between these two researchers. Full-texts were downloaded and consulted only for the included articles.

Data were extracted from the included articles and tabulated in a predefined spreadsheet. The following items were evaluated for each included article: first author's name, year and country of publication, country, study design and period, sample size, population characteristics, age range, proportion of adults aged 60 years or above, travel destination and maximum altitude, number of AMS cases, and association between AMS and age. Some studies reported age as a continuous variable instead of a categorical variable, without providing the proportion of older adults. Nevertheless, these studies were incorporated into the review if the population included travellers aged $\geq 60$ years and if the authors found age to be linearly associated with one or more of the measured outcomes.

The two reviewers (VG and PF) also evaluated the methodological quality of the included studies, using an adapted version of the Newcastle-Ottawa Scale (aNOS) (Supplementary Material, Appendix 2). ${ }^{21}$ Following the strategy from Del Prete et al., reports achieving an aNOS score of 5 or greater were considered high-quality studies. ${ }^{22}$

The lack of comparable outcome measures and the significant methodological heterogeneity among the included studies did not allow the data to be pooled by meta-analysis; therefore, the results were presented as a narrative synthesis.

\section{Results}

The search yielded a total of 532 articles. After reading the titles and abstracts, 48 articles were selected for full reading and 25 full-text articles met the inclusion criteria, , $^{41-17,23-39}$ corresponding to 
26 reports (Fig. 1). Indeed, one article reported data from two assessments, conducted in two different periods; for this reason, these two assessments were considered as two independent research studies. ${ }^{26}$ The main characteristics for each separate study are presented in Table 1, and a complete overview of the articles is included in the supplementary material (Appendix 3, Table S1). All included studies had an observational design, 14 were cohort studies and 11 were cross-sectional. No interventional studies were retrieved.

Most of the research studies (12) were conducted in Asia (mostly in Nepal), followed by America (5), Europe (5), and Africa (3). Among the included papers, enrolment of participants took place between 1975 and 2014. All the reports involved groups of travellers to high-altitude destinations aged 0 to 98 years, and the proportion of older adults ranged between $3.3 \%$ and $100 \%$ (median, $12.5 \%$ ); however, this information was reported in only seven studies. The study samples involved between 97 and 63,076 participants (median, 356) for a total of 88,224 travellers included in this synthesis, comprising several categories of travellers. Most of the reports enrolled trekkers and generic travellers, with 10 studies for each category. The other studies separately analysed business travellers (2), climbers, hikers, mountaineers, and army veterans.

The approaches, methods and quality of the studies were heterogeneous. Several types of research instruments were used to measure the outcomes: 20 studies used a self-administered questionnaire, ${ }^{11,12,14-16,23-26,28,30-39}$ one used face-to-face interviews, ${ }^{27}$ and three used record linkages. ${ }^{4,13,29}$ Additionally, one study's records were completed by the participants' physician. ${ }^{17}$ Even the methodology to diagnose AMS in the travellers differed among the studies. Most of the measurements were performed using the Lake Louise score (LLS, 16 studies), followed by the Environmental Symptoms Questionnaire (AMS-C ESQ, 3 studies), and the Hackett AMS scale (2 studies). In one study, both LLS and AMS-C ESQ were used, while three articles did not indicate the used tool. Overall, the prevalence of AMS throughout the samples ranged between $4.0 \%$ and $76.7 \%$ (median, 29\%) and the prevalence in the older age group was between $14.0 \%$ and $44.2 \%$ (median, $24.4 \%$; data from six reports). 
Regarding the methodological quality assessment, the articles scored between three and seven points in the aNOS scale, with 16 papers accomplishing five or more high-quality criterions. Major reasons for bias across the low-quality reports included the substandard assessment of the outcomes, mostly self-reported through written surveys, the reporting of statistical tests, which were not presented clearly, and the adequacy of the follow-up of the cohorts. A trend in the improvement of methodological quality was detected over time. A more detailed description of the aNOS assessment can be found in Table S2 (see Appendix 3)

As summarized in Table 2, the effect of old age on the extent of AMS varied across the 26 reports. Out of the 26 research studies included in the review, 12 reported a negative correlation between AMS prevalence and age, 11 detected no relationship and three papers indicated that the age of AMS subjects was significantly higher than controls. These three reports that found a positive association between AMS incidence and age included two cross-sectional studies retrospectively conducted on data extracted from the database of the GeoSentinel Surveillance Network and one including QinghaiTibet railroad passengers.

\section{Discussion}

The present systematic review investigated the effect of older age on the development of AMS. The main objective was to assess the susceptibility of older persons to AMS and the reasons for this susceptibility. The database search found a consistent number of studies exploring this association, but a certain variability across them was present. The vast majority of the included reports found a negative correlation between an age of 60 years or above and AMS, or did not find any correlation. Only three articles reported older adults who were more susceptible than their younger counterparts. A previous similar meta-analysis published in 2018 that used a different study design and inclusion criteria, but was not stratified by old age, described no statistically significant association between the risk of AMS and age. However, substantial heterogeneity across the included reports was reported..$^{40}$ Similarly, the findings from the current systematic review were in line with the results 
from Wu et al., but our review added further information on the specific effect of old age on the extent of AMS. In fact, the same authors suggested the need of further research in order to focus on the relationship between AMS and age groups (such as children and elderly). ${ }^{40}$ This study therefore explored the risk for older adults who ascend to high altitudes, specifically considering the elderlyrelated contributors to the extent of AMS (e.g., functional changes, comorbidities, etc.). and also preventing from a deviation in the results due to non-uniform age distributions across different populations enrolled in the reports that study the relationship between AMS and age. ${ }^{40}$

The first pivotal study demonstrating a negative correlation between AMS occurrence and age was published by Hackett and colleagues in 1976. These authors demonstrated not only that incidence and severity of AMS decreased with increasing age, but also that this correlation was present when the results were adjusted for rate of ascent, setting aside the idea that younger trekkers get altitude illness because they climb faster. ${ }^{11}$ Several studies have confirmed these findings and reasons for this decreased susceptibility have been suggested. Fox example, older trekkers might be self-selected to include more healthy persons, ${ }^{12,15}$ tend to minimise altitude symptoms when completing a questionnaire, ${ }^{15}$ do less physical exertion, ${ }^{41}$ climb slowly, ${ }^{38}$ and have lower summit success than younger control subjects. ${ }^{17,39}$ However, none of these possible explanations have been demonstrated clearly or confirmed.

Alongside these behavioural aspects, age-related physiological changes in the human body were suggested as a substrate for protective factors from AMS. Among the latter, the differences in intracranial and intraspinal cerebro-spinal fluid capacity due to the decreased brain size in older person might lead to better toleration of brain swelling through the displacement of cerebro-spinal fluid. This means that older persons experience a lower increase in intracranial pressure when they ascend to high altitudes. ${ }^{26,39,42,43}$ Similarly, the protective role of ageing was ascribed to changes in ventilatory and cardiac responses to hypoxia. ${ }^{44}$

A consistent aspect of the available evidence was the lack of detection of any correlation between age and AMS rate in travellers. Some of these research studies involved populations other than the 
average tourist, such as healthcare professionals, ${ }^{23}$ army veterans, ${ }^{15}$ mountaineers,${ }^{25}$ and climbers. ${ }^{38}$ This has been suggested as a reason for the discrepancies with studies that did report any role of age. ${ }^{25}$ Other researchers ascribed this difference to the small number of older adults in their study samples. ${ }^{16,38}$

Only three studies reported a major effect of old age on the development of AMS. However, the first important feature is that two of these studies only analysed records of patients who presented at travel clinics. $^{4,13}$ Therefore, we must consider the bias to the type of population included in the research studies that may reflect higher AMS prevalence among older persons, or more severe cases. For instance, younger travellers might be less likely to seek medical care when experiencing altitude symptoms, while older travellers might be hospitalised more often when they become ill., 4,29,35

The total number of altitude illnesses recorded from these researches also included cases of highaltitude pulmonary oedema and high-altitude cerebral oedema, which may skew the results of the age distribution of patients. Finally, Boggild and colleagues observed that their finding of the positive role of age in altitude diagnoses should be interpreted cautiously, because denominator data for the age distribution of trekkers in Nepal are lacking. ${ }^{13}$ Similarly, differences in study cohorts must be outlined also for the paper by $\mathrm{Wu}$ et al., which evaluated the occurrence of AMS among QinghaiTibet railroad passengers. The authors explained that older passengers were generally in a rather unconditioned state resulting from their sedentary life-style and may not include self-selected healthy older people. ${ }^{12,14,15}$ Moreover, the younger passengers were physically inactive, while physical exertion is an important contributing cause of AMS in trekkers. ${ }^{11,14,41,45}$

Considering other physical conditions, the influence of old age on the extent of AMS has been unclear for a long time. ${ }^{12}$ Based on the evidence, age does not represent a contraindication for ascending to high altitudes. A protective role of ageing can be assumed, even if it is yet to be confirmed. Indeed, this trend can be also confirmed through the results from studies not involving 60 -year-old subjects or that do not indicate the age range of their cohorts (these studies were therefore not included in this 
review). ${ }^{46,47}$ In this framework, however, a systematic review on the rational clinical examination of AMS reported a two-fold lower risk of AMS for people older than 50 years. ${ }^{48}$

Age per se is not a disease and the ageing-related physiological modification of the human body cannot be considered as a functional impairment. ${ }^{49}$ In comparatively recent years, however, it has been believed that with increasing age the adaptive capacity of maintaining homeostasis to environmental changes, such as hypoxia, through ventilatory and cardiovascular adaptations might be impaired. Ageing causes physiological and functional changes, such as decreased cardiac output and lung vital capacity. ${ }^{50}$

A study exploring ageing and exposure to high altitude in 4,675 subjects found that hypoxia-induced desaturation and cardiac responses decrease with age, while ventilatory responses increase, which compensates for the maintenance of arterial oxygen saturation despite the reduced exchange surface area and muscle strength. ${ }^{44}$ The response to altitude in older persons has been shown to be similar to that of younger subjects, ${ }^{51,52}$ and older travellers seem to tolerate high altitudes well. ${ }^{53}$ However, the case of older adults with pre-existing medical conditions that may worsen during high-altitude sojourns differs from the above findings. ${ }^{49}$ For instance, this may not be true for mountaineers with chronic obstructive pulmonary disease, who were shown to experience a reduction in exercise performance and require oxygen therapy or descend to lower altitudes. ${ }^{54}$

Another aspect that should be considered is the pre-travel care of older travellers. The current evidence suggests that differences in the utilization of pre-travel health advice across age groups are known, $4,22,55,56$ but the studies included in this qualitative synthesis did not provide any information about the pre-travel advice sought by older travellers visiting high-altitude areas. More research should address this point and identify the underlying possible behavioural drivers.

Although the evidence does not conclude that there is an old-age-related higher risk of AMS, older travellers should be aware of the risk of altitude illness. Pre-travel medical advice before travelling remains the first important step for the prevention of travel-associated illness. ${ }^{7,57}$ In case of highaltitude destinations, a travel-tailored cardiologic assessment and acetazolamide prescription are 
necessary. Older travellers should also be advised to ascend with progressive acclimatization to high altitudes. ${ }^{4}$ Some authors also recommended hypoxic exercise evaluation before climbing, ${ }^{44}$ while others remarked that the remoteness of many altitude destinations should form part of the pre-travel risk/benefit assessment for older travellers. ${ }^{53}$ In this respect, it should be clear that 'the older traveller can still climb mountains, it's just that their definition of mountains has changed considerably' ${ }^{50}$ Finally, the use of health technology and smartphone applications should be considered because they could contribute to increasing travellers' awareness, ${ }^{59}$ provide correct and updated health-related information, particularly in remote areas like high-altitude destinations, and even collect data to contribute to big data mining. ${ }^{60}$

It is important to acknowledge some of the limitations of this review. The older population encompasses a great diversity of participants in term of their health status and medical conditions, which possibly influences the representativeness of the population the review intend to reflect. ${ }^{22,60}$ This is of particular relevance in research in travel medicine, with older travellers also differing by their travel characteristics. ${ }^{7,22}$ Disparities in studying ages were present across the included research studies, with some of them only focusing on age as predictors for AMS, but without stratifying by older age. This variability may likely affect this qualitative analysis. Again, substantial heterogeneity was found across studies in terms of design, included cohorts, high-altitude destinations, height, and AMS diagnostic tools. Therefore, the presented results should be interpreted cautiously. Moreover, only English publications were considered in this review, resulting in potential selection bias. However, the most important studies are expected that have been published in English-speaking journals.

Despite these limitations, this is the first systematic review to the best of our knowledge that assesses the potential role of age in AMS with a stratification based on older persons. Moreover, the study methodology was accurate and the systematic search was conducted using gold standard guidelines in several databases. 
In conclusion, old age does not seem to be a contraindication for travelling to high altitudes. Nevertheless, older people, as well as younger travellers, must seek pre-travel advice before travelling to high altitudes and climb using progressive acclimatization. While helpful in summarising what is known on this topic, this systematic review is limited by being narrative in nature and including just a few studies that specifically address the role of old age in the developing of AMS. Nevertheless, the presented synthesis may be useful for health-care professionals in travel medicine to better tailor their appropriate care for the older traveller for the prevention on AMS in this specific population.

\section{Author contributions}

PF conceived the research question; VG and PF developed the search strategy, screened the studies, and extracted the data from the original paper. All authors wrote the manuscript and approved the last version to be published.

\section{Conflict of interests}

Authors have nothing to disclose.

\section{Funding}

No external funding for this manuscript. 


\section{References}

1. Pollard AJ, Murdoch DR. Introduction. The high-altitude medicine handbook. 3rd Ed. Abingdon: Radcliffe Medical Press; 2003.

2. Basnyat B. High Altitude Pilgrimage Medicine. High Alt Med Biol. 2014;15(4):434-39.

3. Centers for Disease Control and Prevention. CDC Yellow Book 2018: Health Information for International Travel. New York: Oxford University Press; 2017.

4. Gautret P, Gaudart J, Leder K, et al. Travel-associated illness in older adults ( $>60 \mathrm{y})$. J Travel Med. 2012;19(3):169-77

5. Keyes LE, Mather L, Duke C, et al. Older age, chronic medical conditions and polypharmacy in Himalayan trekkers in Nepal: an epidemiologic survey and case series. J Travel Med. 2016;23(6).

6. Milanović Z, Pantelić S, Trajković N, Sporiš G, Kostić R, James N. Age-related decrease in physical activity and functional fitness among elderly men and women. Clin Interv Aging. 2013;8:549-56.

7. Bauer IL, Benade EL, Brink GK, et al. The older traveller: A guide for the health professional. Edenvale: South African Society of Travel Medicine (SASTM) Publications; 2016.

8. Committee to Advise on Tropical Medicine and Travel (CATMAT). Statement on Older Travellers. Canada Communicable Disease Report. 2011;37:ACS-2

9. Mieske K, Flaherty G, O'Brien T, MD. Journeys to High Altitude - Risks and Recommendations for Travelers with Preexisting Medical Conditions. J Travel Med. 2010;17(1):48-62.

10. Sharma G, Goodwin J. Effect of aging on respiratory system physiology and immunology. Clin Interv Aging. 2006;1(3):253-60.

11. Hackett PH, Rennie D, Levine HD. The incidence, importance, and prophylaxis of acute mountain sickness. Lancet. 1976;2(7996):1149-55.

12. Honigman B, Theis MK, Koziol-McLain J, et al. Acute mountain sickness in a general tourist population at moderate altitudes. Ann Intern Med. 1993;118(8):587-92.

13. Boggild AK, Costiniuk C, Kain KC, Pandey P. Environmental hazards in Nepal: altitude illness, environmental exposures, injuries, and bites in travelers and expatriates. Journal of Travel Medicine. 2007;14(6):361-8.

14. Wu TY, Ding SQ, Zhang SL, Duan JQ, Li BY, Zhan ZY, Wu QL, Baomu S, Liang BZ, Han SR, Jie YL, Li G, Sun L, Kayser B. Altitude illness in Qinghai-Tibet railroad passengers. High Altitude Medicine \& Biology. 2010;11(3):189-98.

15. Roach RC, Houston CS, Honigman B, et al. How well do older persons tolerate moderate altitude? West J Med. 1995;162(1):32-6. 
16. Ziaee V, Yunesian M, Ahmadinejad Z, et al. Acute mountain sickness in Iranian trekkers around Mount Damavand (5671 m) in Iran. Wilderness Environ Med. 2003 Winter;14(4):2149.

17. Stokes S, Kalson NS, Earl M, et al. Age is no barrier to success at very high altitudes. Age Ageing. 2010;39(2):262-5.

18. Ferrara P. Does age have an effect on the extent of acute mountain sickness (AMS)? PROSPERO $2019 \quad$ CRD42019128976. Available from: http://www.crd.york.ac.uk/PROSPERO/ display_record.php?ID=CRD42019128976

19. Moher D, Liberati A, Tetzlaff J, Altman DG. Preferred reporting items for systematic reviews and meta-analyses: the PRISMA statement. Ann Intern Med. 2009; 151: 264-269

20. United Nations, Department of Economic and Social Affairs, Population Division (2017). World Population Ageing 2017 - Highlights (ST/ESA/SER.A/397).

21. Wells GA, Shea B, O'Connell D, Paterson J, Welch V, Losos M, Tugwell P. The NewcastleOttawa Scale (NOS) for assessing the quality of nonrandomised studies in meta-analyses 2014 (Available at: http://www.ohri.ca/programs/clinical_epidemiology/oxford.asp)

22. Del Prete V, Mateo-Urdiales A, Bueno-Cavanillas A, Ferrara P. Malaria prevention in the older traveller: a systematic review. J Travel Med. 2019;26(7):taz067

23. Montgomery AB, Mills J, Luce JM. Incidence of acute mountain sickness at intermediate altitude. JAMA. 1989;261(5):732-4.

24. Murdoch DR. Symptoms of infection and altitude illness among hikers in the Mount Everest region of Nepal. Aviation, Space, and Environmental Medicine. 1995;66(2):148-51.

25. Schneider M, Bernasch D, Weymann J, Holle R, Bartsch P. Acute mountain sickness: influence of susceptibility, preexposure, and ascent rate. Medicine \& Science in Sports \& Exercise. 2002;34(12):1886-91.

26. Gaillard S, Dellasanta P, Loutan L, Kayser B. Awareness, prevalence, medication use, and risk factors of acute mountain sickness in tourists trekking around the Annapurnas in Nepal: a 12-year follow-up. High Altitude Medicine \& Biology. 2004;5(4):410-9.

27. Vardy J, Vardy J, Judge K. Acute mountain sickness and ascent rates in trekkers above 2500 $m$ in the Nepali Himalaya. Aviation, Space, and Environmental Medicine. 2006;77(7):742-4.

28. Wagner DR, Fargo JD, Parker D, Tatsugawa K, Young TA. Variables contributing to acute mountain sickness on the summit of Mt Whitney. Wilderness \& Environmental Medicine. 2006;17(4):221-8.

29. Leshem E, Pandey P, Shlim DR, Hiramatsu K, Sidi Y, Schwartz E. Clinical features of patients with severe altitude illness in Nepal. Journal of Travel Medicine. 2008;15:315-322.

30. Karinen H, Peltonen J, Tikkanen H. Prevalence of acute mountain sickness among Finnish trekkers on Mount Kilimanjaro, Tanzania: an observational study. High Altitude Medicine \& Biology. 2008;9:301-306. 
31. Croughs M, Van Gompel A, Van den Ende J. Acute mountain sickness in travelers who consulted a pre-travel clinic. Journal of Travel Medicine. 2011;18(5):337-43.

32. Alizadeh R, Ziaee V, Frooghifard L, Mansournia M, Aghsaeifard Z. The Effect of Path and Beginning Time of Ascending on Incidence of Acute Mountain Sickness around Mount Damavand in Iran (5671 m). Neurology Research International 2012;2012:1-6

33. Richalet JP, Larmignat P, Poitrine E, Letournel M, Canouï-Poitrine F. Physiological risk factors for severe high-altitude illness: a prospective cohort study. American Journal of Respiratory and Critical Care Medicine. 2012 Jan 15;185(2):192-8.

34. Salazar H, Swanson J, Mozo K, White AC Jr, Cabada MM. Acute mountain sickness impact among travelers to Cusco, Peru. Journal of Travel Medicine. 2012;19(4):220-5.

35. Croughs M, Van Gompel A, Rameckers S, Van den Ende J. Serious altitude illness in travelers who visited a pre-travel clinic. Journal of Travel Medicine. 2014;21(6):403-9.

36. McDevitt M, McIntosh SE, Rodway G, Peelay J, Adams DL, Kayser B. Risk determinants of acute mountain sickness in trekkers in the Nepali Himalaya: a 24-year follow-up. Wilderness \& Environmental Medicine. 2014;25(2):152-9.

37. Gonggalanzi, Labasangzhu, Nafstad P, Stigum H, Wu T, Haldorsen ØD, Ommundsen K, Bjertness E. Acute mountain sickness among tourists visiting the high-altitude city of Lhasa at 3658 m above sea level: a cross-sectional study. Archives of Public Health. 2016;74:23.

38. Horiuchi M, Endo J, Akatsuka S, Uno T, Jones TE. Prevalence of acute mountain sickness on Mount Fuji: A pilot study. Journal of Travel Medicine. 2016;23(4).pii: taw024

39. Lawrence JS, Reid SA. Risk Determinants of Acute Mountain Sickness and Summit Success on a 6-Day Ascent of Mount Kilimanjaro (5895 m). Wilderness \& Environmental Medicine. 2016;27(1):78-84.

40. Wu Y, Zhang C, Chen Y, Luo YJ. Association between acute mountain sickness (AMS) and age: a meta-analysis. Mil Med Res. 2018;5(1):14.

41. Roach RC, Maes D, Sandoval D, Robergs RA, Icenogle M, Hinghofer-Szalkay H, Lium D, Loeppky JA. Exercise exacerbates acute mountain sickness at simulated high altitude. J. Appl. Physiol. 2000;88:581-585.

42. Ross RT. The random nature of cerebral mountain sickness. Lancet 1985;1:990-991.

43. Roach RC, Hackett PH Frontiers of hypoxia research: acute mountain sickness. J. Exp. Biol. 2001;204: 3161-3170.

44. Richalet JP, Lhuissier FJ. Aging, Tolerance to High Altitude, and Cardiorespiratory Response to Hypoxia. High Alt Med Biol. 2015;16(2):117-24.

45. Maggiorini M, Bühler B, Walter M, Oelz O. Prevalence of acute mountain sickness in the Swiss Alps. BMJ. 1990;301(6756):853-5.

46. Canouï-Poitrine F, Veerabudun K, Larmignat P, Letournel M, Bastuji-Garin S, Richalet JP. Risk Prediction Score for Severe High Altitude Illness: A Cohort Study. PLoS One. 2014; 9(7): e100642. 
47. Pesce C, Leal C, Pinto H, González G, Maggiorini M, Schneider M, Bärtsch P. Determinants of acute mountain sickness and success on Mount Aconcagua (6962 m). High Alt Med Biol. 2005;6(2):158-66.

48. Meier D, Collet TH, Locatelli I, Cornuz J, Kayser B, Simel DL, Sartori C. Does This Patient Have Acute Mountain Sickness?: The Rational Clinical Examination Systematic Review. JAMA. 2017;318(18):1810-1819.

49. Tipping BN. The physiology of ageing. In: Bauer IL, Benade EL, Brink GK, et al. The older traveller: A guide for the health professional. South African Society of Travel Medicine (SASTM) Publications, 2016, p. 10-21

50. Erb BD. The elderly in the wilderness. Wilderness Med Lett 1995;12:6

51. Levine BD, Zuckerman JH, deFilippi CR. Effect of High-Altitude Exposure in the Elderly. Circulation. 1997;96:1224-1232

52. Parati G1, Ochoa JE, Torlasco C, Salvi P, Lombardi C, Bilo G. Aging, High Altitude, and Blood Pressure: A Complex Relationship. High Alt Med Biol. 2015;16(2):97-109.

53. Levine BD. Going High with Heart Disease: The Effect of High Altitude Exposure in Older Individuals and Patients with Coronary Artery Disease. High Alt Med Biol. 2015;16(2):8996.

54. Furian M, Flueck D, Latshang TD, Scheiwiller PM, Segitz SD, Mueller-Mottet S, et al. Exercise performance and symptoms in lowlanders with COPD ascending to moderate altitude: randomized trial. Int J Chron Obstruct Pulmon Dis. 2018;13:3529-3538.

55. Gianfredi V, Moretti M, Gigli M, Fusco-Moffa I. Identikit of the Umbrian traveller: analysis of clinical activity in a travel medicine unit, Italy. Ann Ist Super Sanità 2019; 55(1): 63-67

56. Provost S, Soto JC. Predictors of pretravel consultation in tourists from Quebec (Canada). J Travel Med. 2001;8(2):66-75

57. Lee TK, Hutter JN, Masel J, Joya C, Whitman TJ. Guidelines for the prevention of travelassociated illness in older adults. Tropical Diseases, Travel Medicine and Vaccines 2017;3:10

58. Erb BD. The elderly in the wilderness. Wilderness Med Lett 1995;12:6

59. Provenzano S, Santangelo OE, Armetta F, Gianfredi V, Firenze A. iViaggio: the app for safe traveling. Minerva Medica 2019;110(5):483-5

60. Gianfredi V, Bragazzi NL, Nucci D, Martini M, Rosselli R, Minelli L, Moretti M. Harnessing Big Data for Communicable Tropical and Sub-Tropical Disorders: Implications From a Systematic Review of the Literature. Front Public Health. 2018;6:90

61. Golomb BA, Chan VT, Evans MA, et al. The older the better: are elderly study participants more non-representative? A cross-sectional analysis of clinical trial and observational study samples. BMJ Open 2012;2:e000833. 


\title{
Tables and Figures Legend
}

\author{
Tables
}

Table 1. Characteristics of studies included in the systematic review

Table 2. Main conclusions of studies included in the systematic review

Figures

Figure 1. PRISMA flow chart of the included studies selection process.

Supplementary material

Appendix 1. PRISMA checklist

Appendix 2. Search strategy

Appendix 3. Adapted version of the Newcastle-Ottawa Scale (aNOS) checklist for assessing the quality of non-randomised studies

Appendix 4. Supplementary tables 
Table 1. Characteristics of studies included in the systematic review

\begin{tabular}{|c|c|c|c|c|c|c|c|c|}
\hline $\begin{array}{c}\text { Study, year of } \\
\text { publication }\end{array}$ & Study design & $\begin{array}{c}\text { aNOS } \\
\text { scale } \\
(\max .7)\end{array}$ & $\begin{array}{c}\text { Sampling } \\
\text { period }\end{array}$ & $\begin{array}{c}\text { Sample } \\
\quad N\end{array}$ & $\begin{array}{l}\text { Age of sample } \\
\text { (range or mean) }\end{array}$ & $\begin{array}{c}\text { Population } \geq 60 \\
\text { years old } \\
N(\%)\end{array}$ & Altitude destination & $\begin{array}{c}\text { AMS incidence } \\
\quad N(\%)\end{array}$ \\
\hline Hackett, $1976^{11}$ & Cohort & 6 & 1975 & 278 & $18-71$ & $N R$ & Nepal & $146(52.5)$ \\
\hline Montgomery, $1989^{23}$ & Cross sectional & 3 & 1985 & 454 & $22-65$ & $N R$ & USA & $113(24.9)$ \\
\hline Honigman, $1993^{12}$ & Cohort & 5 & $\begin{array}{c}1998- \\
1991\end{array}$ & 3,158 & $16-87$ & $411(13.0)$ & USA & $789(25.0)$ \\
\hline Roach, $1995^{15}$ & Cohort & 4 & 1992 & 97 & $59-83$ & $\approx 97(100)$ & USA & $16(16.5)$ \\
\hline Murdoch, $1995^{24}$ & Cohort & 5 & $\begin{array}{c}1991- \\
1993\end{array}$ & 283 & $15-65$ & $N R$ & Nepal & $160(56.5)$ \\
\hline Schneider, $2002^{25}$ & Cohort & 4 & $\begin{array}{c}1996 \text { and } \\
1998\end{array}$ & 827 & $N R$ & $27(3.3)$ & Italy & $235(28.4)$ \\
\hline Ziaee, $2003^{16}$ & Cohort & 6 & 2000 & 459 & $13-71$ & $<23(5.0)$ & Iran & $279(60.8)$ \\
\hline Gaillard, $2004(a)^{26}$ & Cohort & 4 & 1986 & 353 & $17-73$ & $N R$ & Nepal & $64(18.0)$ \\
\hline Gaillard, $2004(b)^{26}$ & Cohort & 4 & 1998 & 266 & $17-74$ & $N R$ & Nepal & $11(4.0)$ \\
\hline Vardy, $2006^{27}$ & Cross sectional & 4 & 2003 & 150 & $18-70$ & $N R$ & Nepal & $37(24.7)$ \\
\hline Wagner, $2006^{28}$ & Cross sectional & 5 & 2004 & 359 & $10-76$ & $N R$ & USA & $120(33.4)$ \\
\hline Boggild, $2007^{13}$ & Cross sectional & 7 & $\begin{array}{l}1998- \\
2005\end{array}$ & 10,499 & $0-91$ & $N R$ & Nepal & $498(4.7)$ \\
\hline Leshem, $2008^{29}$ & Cross sectional & 7 & $\begin{array}{l}1999- \\
2006\end{array}$ & 406 & $15-73$ & $N R$ & Nepal & $74(18.2)$ \\
\hline
\end{tabular}




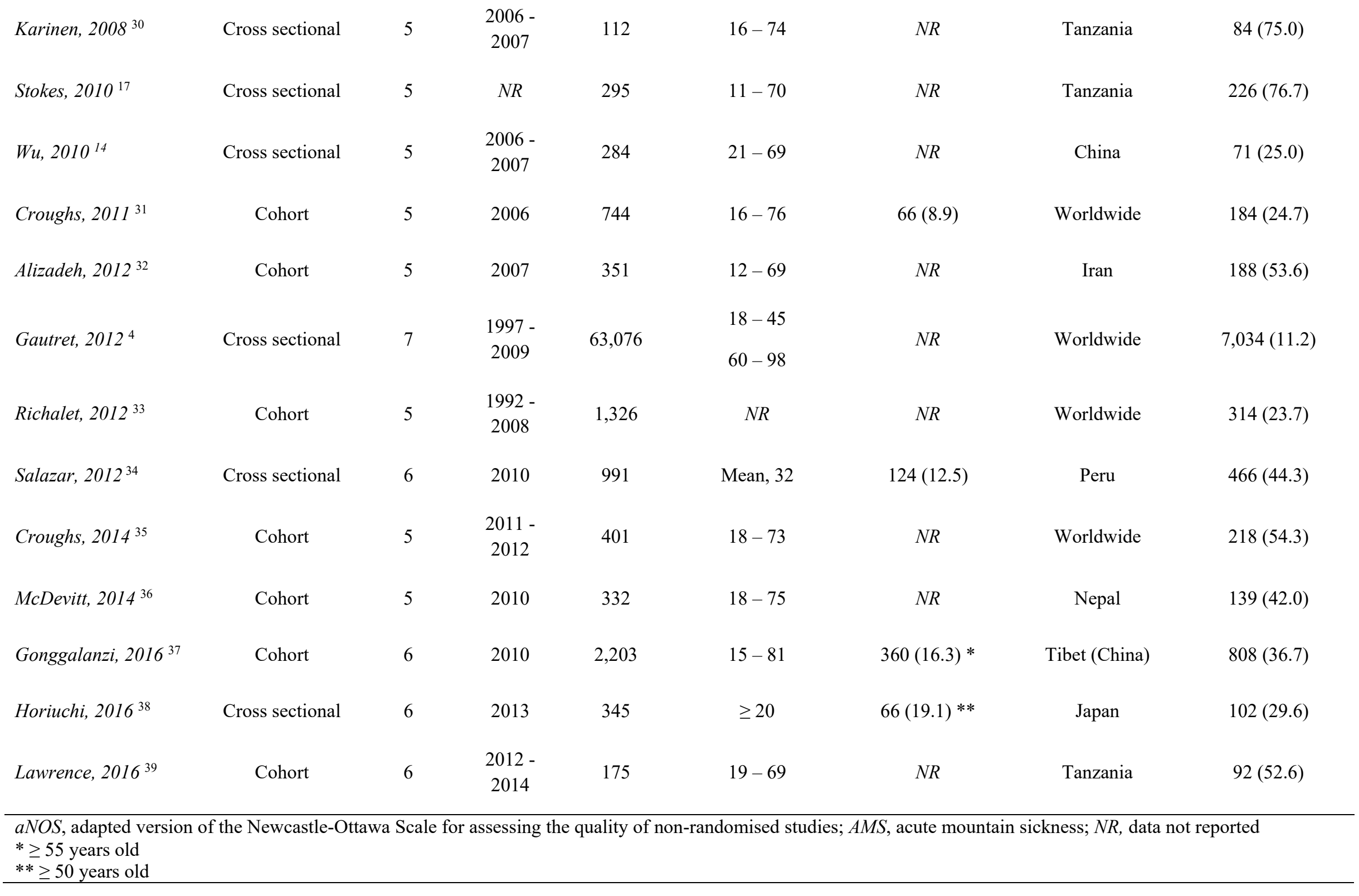


Table 2. Main conclusions of the studies included in the systematic review

Relationship between old age and acute mountain sickness

Negative correlation

Positive correlation

No correlation

\section{Study, year of publication}

Hackett, $1976^{11}$

Honigman, $1993^{12}$

Murdoch, $1995{ }^{24}$

Gaillard, 2004 (a) ${ }^{26}$

Gaillard, 2004 (b) ${ }^{26}$

Wagner, $2006^{28}$

Croughs, $2011^{3}$

Richalet, $2012^{33}$

Salazar, $2012^{34}$

Croughs, $2014^{35}$

McDevitt, $2014^{36}$

Gonggalanzi, $2016^{37}$

Boggild, $2007^{13}$

$\mathrm{Wu}, 2010^{14}$

Gautret, $2012^{4}$

Montgomery, $1989^{23}$

Roach, $1995^{15}$

Schneider, $2002^{25}$

Ziaee, $2003^{16}$

Vardy, $2006^{27}$

Leshem, $2008^{29}$

Karinen, $2008^{30}$

Stokes, $2010^{17}$

Alizadeh, $2012^{32}$

Horiuchi, $2016^{38}$

Lawrence, $2016^{39}$ 